Review

\title{
High-Power, Solid-State, Deep Ultraviolet Laser Generation
}

\author{
Hongwen Xuan ${ }^{1, *}$, Hironori Igarashi ${ }^{2}$, Shinji Ito ${ }^{1}$, Chen $\mathrm{Qu}^{2}$, Zhigang Zhao ${ }^{1}$ and \\ Yohei Kobayashi ${ }^{1}$ \\ 1 The Institute for Solid State Physics, the University of Tokyo, Kashiwanoha 5-1-5, Kashiwa, Chiba 277-8581, \\ Japan; shinji_ito@issp.u-tokyo.ac.jp (S.I.); zhigang@issp.u-tokyo.ac.jp (Z.Z.); yohei@issp.u-tokyo.ac.jp (Y.K.) \\ 2 GIGAPHOTON INC., 400 Yokokurashinden, Oyama, Tochigi 323-8558, Japan; \\ hironori_igarashi@gigaphoton.com (H.I.); chen_qu@gigaphoton.com (C.Q.) \\ * Correspondence: xuan@issp.u-tokyo.ac.jp; Tel.: +81-47-136-3356
}

Received: 8 November 2017; Accepted: 30 January 2018; Published: 3 February 2018

\begin{abstract}
At present, deep ultraviolet (DUV) lasers at the wavelength of fourth harmonics of $1 \mu \mathrm{m}$ $(266 \mathrm{~nm} / 258 \mathrm{~nm})$ and at the wavelength of $193 \mathrm{~nm}$ are widely utilized in science and industry. We review the generation of these DUV lasers by nonlinear frequency conversion processes using solid-state/fiber lasers as the fundamental frequency. A DUV laser at $258 \mathrm{~nm}$ by fourth harmonics generation (FHG) could achieve an average power of $10 \mathrm{~W}$ with a beam quality of $\mathrm{M}^{2}<1.5$. Moreover, $1 \mathrm{~W}$ of average power at $193 \mathrm{~nm}$ was obtained by sum-frequency generation (SFG). A new concept of 193-nm DUV laser generation by use of the diamond Raman laser is also introduced. A proof-of-principle experiment of the diamond Raman laser is reported with the conversion efficiency of $23 \%$ from the pump to the second Stokes wavelength, which implies the potential to generate a higher power $193 \mathrm{~nm}$ DUV laser in the future.
\end{abstract}

Keywords: deep ultraviolet laser; frequency conversion; Raman laser

\section{Introduction}

Deep ultraviolet (DUV) lasers are currently widely employed in various applications. For instance, a DUV laser at $260 \mathrm{~nm}$ has been applied as an "external seed" of a free-electron laser (FEL) with output wavelengths as short as $4.3 \mathrm{~nm}$, which would make it possible to do the scientific research beyond the carbon K-edge [1]. In the industrial applications, laser machining of wide bandgap materials would be also beneficial from the DUV lasers owing to their characteristics of high photon energy [2].

In the past decades, with the fast development of the solid-state lasers and the nonlinear optical crystals, high-power DUV lasers at $266 \mathrm{~nm} / 258 \mathrm{~nm}$ have been studied by many research groups fruitfully [3-17]. These DUV lasers are usually generated by fourth-harmonics generation (FHG) of the near-infrared (NIR) laser at $1 \mu \mathrm{m}$ as shown in Figure 1. Until now, the highest average output power of these DUV lasers was $40 \mathrm{~W}$ at the wavelength of $266 \mathrm{~nm}$, of which the fundamental light was a high-power $\mathrm{Nd}: \mathrm{Y}_{3} \mathrm{Al}_{5} \mathrm{O}_{12}(\mathrm{Nd}: \mathrm{YAG})$ laser at $1064 \mathrm{~nm}$ and the nonlinear optical crystal was a $\mathrm{CsLiB}_{6} \mathrm{O}_{10}$ (CLBO) [8]. In the scientific and industrial applications, the beam quality of the DUV laser is also an important parameter. Particularly, the beam quality of the DUV laser dramatically affects the laser machining results. The beam quality of the DUV laser is determined by that of the fundamental laser and the crystal for the frequency conversion. Recently, a high-power DUV laser (>10 W) at $258 \mathrm{~nm}$ was reported with a beam quality of $\mathrm{M}^{2}<1.5$, which was generated by FHG of a Yb:YAG laser at $1030 \mathrm{~nm}$ using the CLBO crystal [13]. This laser would lead to a better laser machining result compared to the previous DUV lasers with larger $\mathrm{M}^{2}$. 


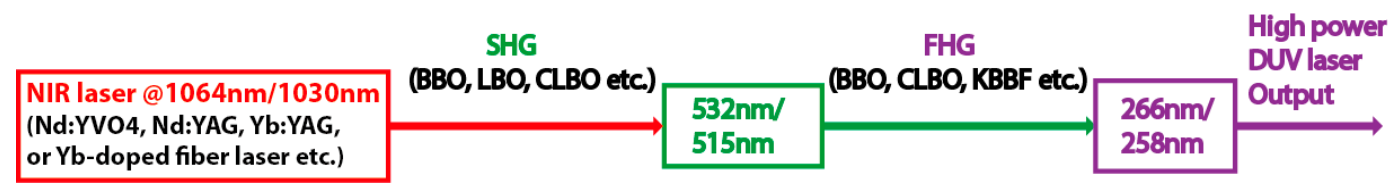

Figure 1. Schematic setup of the solid-state DUV laser by FHG of 1- $\mu$ m laser (DUV: deep ultra-violet; SHG: second-harmonics generation; FHG: fourth-harmonics generation; $\mathrm{YAG}: \mathrm{Y}_{3} \mathrm{Al}_{5} \mathrm{O}_{12}$; BBO: $\beta-\mathrm{BaB}_{2} \mathrm{O}_{4} ; \mathrm{LBO}: \mathrm{LiB}_{3} \mathrm{O}_{5} ; \mathrm{CLBO}: \mathrm{CsLiB}_{6} \mathrm{O}_{10} ; \mathrm{KBBF}: \mathrm{KBe}_{2} \mathrm{BO}_{3} \mathrm{~F}_{2}$ ).

In terms of the solid-state DUV laser at $193 \mathrm{~nm}$, the laser machining as well as other applications such as mask-inspection or lithography require a high-power DUV laser output $[4,18,19]$. The highest output power of the continuous-wave (CW) 193-nm laser was $120 \mathrm{~mW}$ by stages of sum-frequency generation (SFG) between DUV lasers (wavelength longer than $193 \mathrm{~nm}$ ) and corresponding NIR lasers [4]. For the pulsed lasers, a DUV laser at $193 \mathrm{~nm}$ with average power of $300 \mathrm{~mW}$ was reported and had already been applied to be the seed of a hybrid ArF excimer laser [2,12]. By use of this hybrid ArF excimer laser schematics, both high power $(>100 \mathrm{~W})$ and high coherence could be obtained at the same time, which consists of a solid-state DUV laser seed and an ArF excimer amplifier [2]. A high-power solid-state DUV seeding laser with high coherence is beneficial to the final output of the hybrid ArF excimer laser, and it would also result in suppressing the amplified spontaneous emission (ASE) of the amplifier.

SFG is the most popular method to generate the DUV laser at $193 \mathrm{~nm}$. Typically, a DUV laser, of which the wavelength is usually from $200 \mathrm{~nm}$ to $300 \mathrm{~nm}$, and a NIR laser play the roles of SFG lasers in the nonlinear crystals to generate the 193-nm DUV laser. So far, the highest output power at $193 \mathrm{~nm}$ by following the above SFG schematics was $1 \mathrm{~W}$ by two stages of SFG [20]. As aforementioned, there is still great demand for power scaling of the solid-state DUV laser at $193 \mathrm{~nm}$. Thus, by the SFG schematics, the requirement is to increase both the DUV laser (wavelength longer than $193 \mathrm{~nm}$ ) power and the NIR laser power at the same time. By choosing the appropriate high-power fundamental laser at $1 \mu \mathrm{m}$ as well as the nonlinear optical crystals, the average power of the DUV laser at the fourth harmonics of $1 \mu \mathrm{m}$ could be obtained to be at the 10-watts level in the previous reports. On the other side, the power scaling of the NIR laser is another aspect to increase the average power of the 193-nm DUV laser. Due to the lack of the high-power amplification solution of the NIR laser (for example at $1553 \mathrm{~nm}$ ), nonlinear frequency processes such as optical parameter oscillation (OPO) could be applied to build a wavelength converter by shifting the wavelength from $1 \mu \mathrm{m}$ to the desired wavelength as well as obtaining relative higher power [21]. Recently, a diamond Raman laser showed its ability in achieving a high power and a high conversion efficiency at the 1st Stokes of the 1- $\mu \mathrm{m}$ laser [22,23], which implies the possibility to be applied in the 193-nm DUV laser generation because of its high Raman gain and large frequency shift.

In this paper, we present a review on the current status of the high-power solid-state DUV lasers. The high-power DUV laser at $258 \mathrm{~nm}$ was generated by FHG from $1 \mu \mathrm{m}$. The development of the 193-nm laser was demonstrated by stages of SFG. In order to scale the DUV laser power effectively, a new concept of the 193-nm DUV laser generation is presented based on the diamond Raman laser.

\section{DUV Laser Generated by FHG of the 1- $\mu$ m NIR Laser}

Figure 1 depicts the schematic setup of the solid-state DUV laser at the FHG wavelength $(258 \mathrm{~nm}$ or $266 \mathrm{~nm}$ ) of 1- $\mu \mathrm{m}$ laser, and Table 1 lists the typical results by following this setup including a result by SFG in the $\mathrm{LiB}_{3} \mathrm{O}_{5}(\mathrm{LBO})$ crystal. So far, the highest average output power of it was $40 \mathrm{~W}$, which was reported by M. Nishioka et al. in the year 2003 [8] as the improvement result of their 20.5 W DUV laser in 2000 [9]. The fundamental laser was an Q-switched diode-pumped Nd:YAG green laser at the wavelength of $532 \mathrm{~nm}$. The $40 \mathrm{~W} 266 \mathrm{~nm}$ laser was obtained by second-harmonics generation (SHG) in a CLBO crystal. Nevertheless, the beam quality of the DUV laser was not good enough because the 
green laser had a $\mathrm{M}^{2}$ of 10 [8]. In 2006, G. Wang et al. reported a $28.4 \mathrm{~W}$ average power DUV laser at $266 \mathrm{~nm}$ by SHG of a $532 \mathrm{~nm}$ laser with $\mathrm{M}^{2}=6.5$ [10]. Q. Liu et al. presented the result of their DUV laser with average output power of $14.8 \mathrm{~W}$ by FHG of a Nd:YVO laser at the wavelength of $1064 \mathrm{~nm}$ [3]. The output power of the fundamental Nd:YVO laser was $160 \mathrm{~W}$ with the beam quality of $M_{x}^{2}=1.28$ and $M_{y}^{2}=1.21$. After SHG, the beam quality of green laser was $M_{x}^{2}=1.44$ and $M_{y}^{2}=1.28$. However, the beam quality of DUV laser will be remarkably decayed due to the large walk-off effect of the $\beta-\mathrm{BaB}_{2} \mathrm{O}_{4}$ (BBO) crystal for FHG to $266 \mathrm{~nm}$ [6]. O. Novak et al. reported a 6-W DUV laser at $257.5 \mathrm{~nm}$ by FHG in a CLBO crystal which effectively improved the DUV laser beam quality due to the smaller walk-off effect of the CLBO crystal [11] comparing to the previous results using BBO crystals [3-6]. However, the estimated $\mathrm{M}^{2}$ of it was still more than 1.5. From the above-reported results, the key point to obtain a high-power, high-beam quality DUV laser is to choose a high power fundamental laser at $1 \mu \mathrm{m}$ with a good beam quality and proper nonlinear crystals with a smaller walk-off effect for SHG and FHG. A fundamental laser with a good beam quality is crucial for the final DUV beam quality as well as the nonlinear crystal with a smaller walk-off angle.

Table 1. Typical results of the solid-state DUV laser at $258 \mathrm{~nm} \& 266 \mathrm{~nm}$ (NIR: near-infrared; DUV: deep ultra-violet; FHG: fourth-harmonics generation; $\mathrm{BBO}: \beta-\mathrm{BaB}_{2} \mathrm{O}_{4} ; \mathrm{CLBO}: \mathrm{CsLiB}_{6} \mathrm{O}_{10} ; \mathrm{KBBF}: \mathrm{KBe}_{2} \mathrm{BO}_{3} \mathrm{~F}_{2}$; NSBBF: $\mathrm{NaSr}_{3} \mathrm{Be}_{3} \mathrm{~B}_{3} \mathrm{O}_{9} \mathrm{~F}_{4} ; \mathrm{YAB}: \mathrm{YAl}_{3}\left(\mathrm{BO}_{3}\right)_{4}$; SFG: sum-frequency generation).

\begin{tabular}{ccccccc}
\hline $\begin{array}{c}\text { Wavelength } \\
(\mathbf{n m})\end{array}$ & FHG Crystal & Power/Energy & Repetition Rate & $\begin{array}{c}\text { NIR to FHG } \\
\text { Efficiency (\%) }\end{array}$ & $\mathbf{M}^{\mathbf{2}}$ (DUV) & Reference \\
\hline 266 & $\mathrm{BBO}$ & $14.8 \mathrm{~W}$ & $100 \mathrm{kHz}(\sim \mathrm{ns})$ & $\sim 10$ & $>1.5$ & {$[3]$} \\
257 & $\mathrm{BBO}$ & $3.2 \mathrm{~W}$ & $30 \mathrm{kHz}(\sim \mathrm{ns})$ & 14.5 & $>1.1$ & {$[4]$} \\
257.7 & $\mathrm{BBO}$ & $2.74 \mathrm{~mJ}$ & $1 \mathrm{kHz}(\sim \mathrm{ps})$ & 9.7 & $<3$ & {$[5]$} \\
257 & $\mathrm{BBO}$ & $1.1 \mathrm{~W}$ & $14.5 \mathrm{kHz}(\sim \mathrm{ns})$ & $\sim 31$ & & {$[6]$} \\
258 & $\mathrm{BBO}$ & $4.6 \mathrm{~W}$ & $796 \mathrm{kHz}(\sim \mathrm{fs})$ & $\sim 5.8$ & $1.3 \times 1.6$ & {$[7]$} \\
266 & $\mathrm{CLBO}$ & $40 \mathrm{~W}$ & $7 \mathrm{kHz}(\sim \mathrm{ns})$ & $<10$ & $>10$ & {$[8]$} \\
266 & CLBO & $20.5 \mathrm{~W}$ & $10 \mathrm{kHz}(\sim \mathrm{ns})$ & 14 & $>10$ & {$[9]$} \\
266 & CLBO & $28.4 \mathrm{~W}$ & $10 \mathrm{kHz}(\sim \mathrm{ns})$ & $<22$ & $>6.24$ & {$[10]$} \\
257.5 & CLBO & $6 \mathrm{~W}$ & $100 \mathrm{kHz}(\sim \mathrm{ps})$ & 10 & $<1.5$ & {$[11]$} \\
258 & CLBO & $3 \mathrm{~W}$ & $6 \mathrm{kHz}(\sim \mathrm{ns})$ & 35 & $<1.5$ & {$[12]$} \\
258 & CLBO & $10.5 \mathrm{~W}$ & $10 \mathrm{kHz}(\sim \mathrm{ns})$ & 31 & $>2$ & {$[13]$} \\
266 & KBBF & $7.86 \mathrm{~W}$ & $10 \mathrm{kHz}(\sim \mathrm{ns})$ & $<10$ & 6.3 & {$[15]$} \\
266 & YAB & $5.05 \mathrm{~W}$ & $65 \mathrm{kHz}(\sim \mathrm{ns})$ & 14 & {$[16]$} \\
266 & LBO(SFG $)$ & $3.3 \mathrm{~W}$ & $1 \mathrm{MHz}(\sim \mathrm{ns})$ & 14 & {$[17]$} \\
266 & NSBBF & $280 \mu \mathrm{J}$ & $10 \mathrm{~Hz}(\sim \mathrm{ps})$ & 36 & & \\
\hline
\end{tabular}

Due to the thermal lens effect in the solid-state lasers, if the heating management is insufficient, it is not easy to obtain the solid-state laser with a high power and a high beam quality simultaneously. Recently, with the development of the thin disk laser and single-crystal fiber (SCF) laser, a high-power laser at the fundamental wavelength $(1 \mu \mathrm{m})$ had been realized with a good beam quality even with a $\mathrm{TEM}_{00}$ mode beam [4,24], which would be good candidates for the fundamental of the DUV laser generation. Another candidate for the fundamental is the high-power fiber laser which could be achieved by coherent beam combination with $\mathrm{M}^{2}$ value less than 1.1 on both axes of the beam. Hence, 4.6 W DUV laser at $258 \mathrm{~nm}$ was obtained by FHG of this fiber laser with an $\mathrm{M}^{2}$ value of $1.3 \times 1.6$, which is the highest average power of the femtoseconds laser at this DUV wavelength so far [7]. Additionally, using the fiber laser as the fundamental, 100-W ultraviolet laser at $343 \mathrm{~nm}$ has also been obtained by third harmonics generation with $\mathrm{M}^{2}<1.4$ [25]. Nevertheless, these high-power fiber lasers were achieved by the coherent beam combination requiring electronics systems to lock different amplifier channels, which increases the cost and the complexity.

Many kinds of crystals could be used for FHG such as BBO, CLBO, $\mathrm{KBe}_{2} \mathrm{BO}_{3} \mathrm{~F}_{2}(\mathrm{KBBF}), \mathrm{YAl}_{3}$ $\left(\mathrm{BO}_{3}\right)_{4}(\mathrm{YAB}), \mathrm{NaSr}_{3} \mathrm{Be}_{3} \mathrm{~B}_{3} \mathrm{O}_{9} \mathrm{~F}_{4}$ (NSBBF) etc. as shown in Table 1. For FHG from $515 \mathrm{~nm}$ to $258 \mathrm{~nm}$, the efficient nonlinear coefficient $\left(\mathrm{d}_{\mathrm{eff}}\right)$ of the $\mathrm{BBO}$ crystal is the highest one among these crystals [15]. However, the BBO crystal also has the largest walk-off angle which will lead to a decline of the DUV 
laser beam quality comparing to use the crystal with a smaller walk-off angle such as CLBO. LBO is also an excellent nonlinear crystal which is always applied to the SHG from the NIR to the green. The DUV laser is usually realized by two stages of SFG in the LBO crystals since there is no phase-matching angle for LBO to convert the green laser at $515 \mathrm{~nm}$ or $532 \mathrm{~nm}$ to the DUV directly by SHG [16]. Recently, the NSBBF crystal has also shown its potential to obtain a high conversion efficiency from $532 \mathrm{~nm}$ to $266 \mathrm{~nm}$. The walk-off angle and $d_{\text {eff }}$ of the NSBBF are almost similar to those of CLBO [17].

The conversion efficiency from fundamental NIR to DUV is from $5 \%$ to $36 \%$ according to the reported results in Table 1. Increasing the conversion efficiency will reduce the burden on the design and setup of the fundamental laser amplifier as well as the electric power consumption. A good beam quality of the fundamental laser will also contribute to the increasing of the conversion efficiency as well as the appropriate power intensity of the NIR and green laser in the SHG and FHG process, respectively. The highest conversion efficiencies from NIR to green and green to DUV laser by use of CLBO crystal are $70 \%$ and around $50 \%$, respectively [12], which corresponds to the conversion efficiency of 35\% from fundamental to DUV. In this report, the average output power of this DUV laser was $3 \mathrm{~W}$ which was limited by the fundamental NIR laser power. Recently, a DUV laser with $10.5 \mathrm{~W}$ average power output was reported, and the conversion efficiency was $31 \%$ from fundamental to DUV [13]. Its beam quality was the best for the $258 \mathrm{~nm} / 266 \mathrm{~nm}$ DUV laser with the average power higher than $10 \mathrm{~W}$, of which the $\mathrm{M}^{2}$ is less than 1.5.

This high-power, high-beam quality DUV laser is also following the schematic setup as depicted in Figure 1. In detail, the fundamental laser was at $1030 \mathrm{~nm}$ which was from a master oscillator power amplifier (MOPA). The frequency conversion stages consisted of a noncritical phase-matching (NCPM) LBO crystal $\left(5 \times 5 \times 30 \mathrm{~mm}^{3}\right)$ for SHG from $1030 \mathrm{~nm}$ to $515 \mathrm{~nm}$ and a CLBO crystal for FHG from $515 \mathrm{~nm}$ to $258 \mathrm{~nm}$. The seed laser of the MOPA was a distributed-feedback (DFB) laser diode (LD), and it was electrically modulated by a pulse generator with the repetition rate of $160 \mathrm{kHz}$ and with a pulse duration of $10 \mathrm{~ns}$. The repetition rate was lowered down to $10 \mathrm{kHz}$ by an acousto-optic modulator (AOM). After 3 stages of fiber amplifiers, the signal was amplified to about $2 \mathrm{~W}$. One stage of Yb:YAG ceramics thin rod (CTR) amplifier and one stage of Yb:YAG SCF amplifier (TARANIS, Fibercryst Inc., Décines-Charpieu, France) were used as the main amplifiers. The Yb:YAG CTR was in the dimension of $\Phi=1 \mathrm{~mm} \times \mathrm{L}=40 \mathrm{~mm}$ with $\mathrm{Yb}^{3+}$ ion doping of 1 at. \% as well as the Yb:YAG SCF. The pump source of this stage was a $940 \mathrm{~nm}$ LD with $100 \mathrm{~W}$ output and the output power was $25 \mathrm{~W}$ by use of a double-pass configuration. The Yb:YAG SCF amplifier was pumped by a $200 \mathrm{~W} L D$ at the wavelength of $969 \mathrm{~nm}$ which was stabilized with a volume Bragg grating. The Yb:YAG SCF amplifier was a single pass configuration with $35 \mathrm{~W}$ output at $100 \mathrm{~W}$ pumping. The conversion efficiency of SHG from NIR to green and FHG from green to DUV was $73 \%$ and $42 \%$, respectively, corresponding to a conversion efficiency of $31 \%$ from NIR to DUV. This was highest conversion efficiency for the DUV lasers with average powers of more than $10 \mathrm{~W}$. Furthermore, the beam quality was near-diffraction-limited for both amplifiers (Yb:YAG CTR: $M_{x}^{2}=1.06$ and $M_{y}^{2}=1.03$; Yb:YAG SCF: $M_{x}^{2}=1.02$ and $M_{y}^{2}=1.04$ ). Hence, the DUV laser had an excellent beam quality owing to the good beam quality of the fundamental laser and the optimized frequency conversion stages. The measured value of $\mathrm{M}^{2}$ was $M_{x}^{2}=1.02$ and $M_{y}^{2}=1.05$ for DUV laser at $3 \mathrm{~W}$. Although the DUV beam became a little worse at 9-10 W $\left(M_{x}^{2}=1.37\right.$ and $\left.M_{y}^{2}=1.46\right)$, it is still the best laser beam quality with $\mathrm{M}^{2}<1.5$ for the DUV laser power more than $10 \mathrm{~W}$ [13].

The average power of the NIR laser still has the potential to be improved to tens of watts such as $70 \mathrm{~W}$ [26] if the double-pass configuration could be utilized for the Yb:YAG SCF amplifier stage. Hence, if the conversion efficiency of $31 \%$ from NIR to DUV could be still maintained at this higher power condition, the average output power of the DUV laser at $258 \mathrm{~nm}$ could be more than $20 \mathrm{~W}$, which would be a remarkable power level for the DUV laser and lead to the unanticipated DUV laser machining results. Moreover, for high-power DUV laser, the UV damage of the nonlinear crystal, including the windows for CLBO crystal and the mirrors, is another important parameter for long term and stable operation. On the other hand, the beam quality of this higher power DUV laser would 
become worse due to more serious thermal and nonlinear effects. Hence, the frequency conversion processes should be carefully designed to mitigate the aforementioned effects. Thus, a high-power DUV laser at the FHG of $1 \mu \mathrm{m}$ with a good beam quality could be obtained and will be beneficial for obtaining the shorter wavelength DUV lasers such as $193 \mathrm{~nm}$ by SFG.

\section{DUV Laser at $193 \mathrm{~nm}$}

The reported typical results of the solid-state DUV laser at $193 \mathrm{~nm}$ in the past decades are listed in Table 2.

Table 2. Typical results of the solid-state DUV laser at $193 \mathrm{~nm}$ (CW: continuous-wave; $\mathrm{KABO}: \mathrm{K}_{2} \mathrm{Al}_{2} \mathrm{~B}_{2} \mathrm{O}_{7}$ ).

\begin{tabular}{cccccc}
\hline Wavelength $(\mathbf{n m})$ & Method & Crystal & Power/Engergy & Repetition Rate & Reference \\
\hline 193 & SHG & KBBF & $15 \mathrm{~mW}$ & $\mathrm{CW}$ & {$[27]$} \\
193 & SHG & KBBF & $2.23 \mathrm{~mW}$ & $8 \mathrm{kHz}(\sim \mathrm{ns})$ & {$[28]$} \\
193 & SHG & KBBF & $1.05 \mathrm{~W}$ & $1 \mathrm{kHz}(\sim \mathrm{ps})$ & {$[29]$} \\
193 & SHG & KBBF & $0.2 \mathrm{~W}$ & $6 \mathrm{kHz}(\sim \mathrm{ns})$ & {$[30]$} \\
193.4 & SFG $(234.1 \mathrm{~nm}+1110 \mathrm{~nm})$ & CLBO & $120 \mathrm{~mW}$ & $\mathrm{CW}$ & {$[18]$} \\
193 & SFG $(221 \mathrm{~nm}+1547 \mathrm{~nm})$ & CLBO & $140 \mathrm{~mW}$ & $200 \mathrm{kHz}(\sim \mathrm{ns})$ & {$[31]$} \\
193.5 & SFG $(221 \mathrm{~nm}+1553 \mathrm{~nm})$ & CLBO & $310 \mathrm{~mW}$ & $6 \mathrm{kHz}(\sim \mathrm{ns})$ & {$[12]$} \\
193 & SFG $(226 \mathrm{~nm}+1342 \mathrm{~nm})$ & CLBO & $230 \mathrm{~mW}$ & $6 \mathrm{kHz}(\sim \mathrm{ns})$ & {$[32]$} \\
193 & SFG $(221 \mathrm{~nm}+1553 \mathrm{~nm})$ & CLBO & $1.02 \mathrm{~W}$ & $10 \mathrm{kHz}(\sim \mathrm{ns})$ & {$[20]$} \\
193 & SFG $(235.8 \mathrm{~nm}+1064 \mathrm{~nm})$ & KABO & $0.2 \mathrm{~W}$ & $10 \mathrm{kHz}(\sim \mathrm{ns})$ & {$[33]$} \\
193.4 & SFG $(266 \mathrm{~nm}+708.6 \mathrm{~nm})$ & BBO & $2.5 \mathrm{~mW}$ & $5 \mathrm{kHz}(\sim \mathrm{ns})$ & {$[19]$} \\
193 & SFG $(258 \mathrm{~nm}+774 \mathrm{~nm})$ & BBO & $2 \mu \mathrm{J}$ & $20 \mathrm{~Hz}(\sim \mathrm{fs})$ & {$[34]$} \\
193 & SFG $(213 \mathrm{~nm}+2100 \mathrm{~nm})$ & LBO & $770 \mu \mathrm{J}$ & $60 \mathrm{~Hz}(\sim \mathrm{ns})$ & {$[21]$} \\
\hline
\end{tabular}

Two methods are usually applied to generate the solid-state DUV laser at the wavelength shorter than $200 \mathrm{~nm}$. One is by SHG directly from a longer wavelength; the other one is by stages of SFG. T. Thao Tran et al. and Y. Yang et al., respectively, summarized the nonlinear optical materials for DUV generation from 5 th to 7 th harmonics of Nd:YAG laser at $1064 \mathrm{~nm}[35,36]$ by SHG and SFG including $\mathrm{CLBO}, \mathrm{KBBF}, \mathrm{LBO}, \mathrm{BBO}, \mathrm{K}_{2} \mathrm{Al}_{2} \mathrm{~B}_{2} \mathrm{O}_{7}(\mathrm{KABO})$ etc. Recently, coherent radiation in the vacuum ultraviolet (VUV) region was generated with a wavelength as short as $121 \mathrm{~nm}$ in strontium tetra borate (SBO) by "random quasi-phase matching" (RQPM), which was the shortest wavelength generated by second-order nonlinear optical process in a solid-state material [37]. However, this SBO crystal does not fit for the high-power DUV laser generation due to the low efficiency of around $10^{-5}$.

Table 2 summarizes the typical results of the solid-state DUV laser at $193 \mathrm{~nm}$ by use of the different nonlinear crystals. Among the above crystals, the KBBF crystal is currently known as the only one, enabling high power and short wavelength directly by SHG [28-30,36,38,39]. For the application of seeding the hybrid ArF excimer laser, the DUV laser should be at the wavelength of $193 \mathrm{~nm}$. In $2008, \mathrm{H}$. Zhang reported the result of $2.23 \mathrm{~mW}$ at $193 \mathrm{~nm}$ average power output directly by SHG in KBBF [28]. Later, Kanai et al. reported a 1.05 W 193-nm laser also by SHG in KBBF with the pulse duration of several hundred of picoseconds, of which the fundamental laser was from a Ti:Sapphire amplifier [29]. This is also the highest average power of 193-nm laser by SHG until now. In 2012, S. Ito et al. presented a $0.2 \mathrm{~W} 193-\mathrm{nm}$ laser by SHG in KBBF with nanoseconds pulse which is suitable for seeding the ArF laser [30]. In addition, CW DUV laser at $193 \mathrm{~nm}$ was reported by M. Scholz et al. with the output power of $15 \mathrm{~mW}$ in KBBF by SHG with which the fundamental laser was from an external cavity laser [27].

The wavelength conversion of SHG to $193 \mathrm{~nm}$ by using KBBF was successfully demonstrated by the aforementioned groups. However, the KBBF should be packed in a prism coupling device (PCD) consisting of $\mathrm{CaF}_{2}$ or $\mathrm{SiO}_{2}$ prisms to achieve the phase-matching condition [14,29]. Moreover, KBBF is significantly difficult to be grown into single crystal because of the weak interaction of alkali metal and fluorine cations [35,36], which limit its potential to be grown into large dimension and to be applied in generating a higher power 193-nm laser for seeding the hybrid ArF laser. Hence, the SFG process in other crystals is the practical method for high-power 193-nm laser generation. The cut-off 
wavelength of DUV laser generated by SHG in BBO is limited to $205 \mathrm{~nm}$ by a phase matching condition although its absorption edge could reach down to $189 \mathrm{~nm}$ [40]. Nevertheless, the BBO crystal could be used in SFG process to generate the $193 \mathrm{~nm}$ laser. J.J. Jacob et al. reported a $193.4 \mathrm{~nm}$ laser by SFG between a $266 \mathrm{~nm}$ and a $708.6 \mathrm{~nm}$ laser with the output power $2.5 \mathrm{~mW}$ [19]. Even more than 20 years ago, femtoseconds $193 \mathrm{~nm}$ laser was generated in BBO by SFG between $258 \mathrm{~nm}$ and $774 \mathrm{~nm}$ [34]. Another drawback of BBO crystal is a large walk-off effect, which would deteriorate the SFG laser beam quality. LBO crystal could also be used for 193-nm laser generation if the wavelengths fulfilling the phase-matching condition. Hamilton et al. reported the 193-nm laser generation between $213 \mathrm{~nm}$ and $2100 \mathrm{~nm}$ in LBO by SFG with the energy of $770 \mu \mathrm{J}$ [21]. LBO has a smaller walk-off angle leading to a better beam quality. However, the efficient nonlinear coefficient is smaller than that of the $\mathrm{BBO}$ or CLBO crystal, which limits the DUV laser power scaling. KABO is also an excellent nonlinear optical crystal for DUV laser generation. Umemura et al. reported a $193 \mathrm{~nm}$ laser with the average output power of $0.2 \mathrm{~W}$ which could run stable for 50 hours although $\mathrm{KABO}$ has the smallest $\mathrm{d}_{\text {eff }}$ comparing to BBO, LBO, and CLBO [33]. For the CLBO crystal, J. Sakuma reported a $120 \mathrm{~mW}$ DUV laser output at $193.4 \mathrm{~nm}$ by SFG between $234.1 \mathrm{~nm}$ and $1110 \mathrm{~nm}$, which is the highest solid-state CW 193-nm laser until now [18]. Other results of $193 \mathrm{~nm}$ generation by SFG in CLBO also could reach to the average power from $100 \mathrm{~mW}$ to $300 \mathrm{~mW}[12,31,32]$. CLBO has a larger $\mathrm{d}_{\text {eff }}$ than LBO and a smaller walk-off angle than $\mathrm{BBO}$, which means it could lead to a higher power DUV laser with better beam quality at the same time. Hence, the CLBO crystal is a suitable crystal for 193-nm laser generation. However, CLBO is more hygroscopic comparing to BBO or LBO crystals. Packaging the CLBO crystal into a cell, heating the crystal up to more than $150{ }^{\circ} \mathrm{C}$, and purging it by use of noble gas is the solution to avoid these problems [41]. In addition, the previous CLBO crystal for FHG to DUV laser at $258 \mathrm{~nm}$ was also treated in the above conditions.

In terms of the experimental setup, the two laser wavelengths for SFG should be chosen carefully in order to satisfy the phase-matching condition of the nonlinear optical crystals. The Nd:YAG, Yb:YAG, $\mathrm{Nd}: \mathrm{YVO}_{4}$ and $\mathrm{Yb}$-doped fiber lasers could achieve both high power and high beam quality. According to the published results for generating $193 \mathrm{~nm}$, these NIR lasers were used for the fundamental of a DUV laser with the wavelength longer than $193 \mathrm{~nm}$ such as $258 \mathrm{~nm}$ (4th harmonics) [12], $213 \mathrm{~nm}$ (5th harmonics) [21]. By use of nonlinear processes such as OPO, the 1- $\mu \mathrm{m}$ NIR laser is converted to longer wavelengths $[19,21,28]$, which extends the available laser wavelengths for SFG. Using the Er-doped fiber laser at $1550 \mathrm{~nm}$ together with the 1- $\mu \mathrm{m}$ NIR laser, the final target of the $193 \mathrm{~nm}$ laser is achieved without involving the complex and unstable nonlinear OPO process [12,31,42].

Recently, $310 \mathrm{~mW}$ DUV laser at $193 \mathrm{~nm}$ was generated by stages of SFG in the CLBO crystals. The schematic setup for this $193 \mathrm{~nm}$ laser was shown in Figure 2. The 193-nm laser was generated by two stages of SFG process between a $258 \mathrm{~nm}$ laser generated by FHG of a $1030 \mathrm{~nm}$ laser and a $1553 \mathrm{~nm}$ laser. The $1030 \mathrm{~nm}$ laser was based on an $\mathrm{Yb}$-doped hybrid amplifier and the $1553 \mathrm{~nm}$ laser was from an Er-doped fiber amplifier. The $1030 \mathrm{~nm}$ laser and the $1553 \mathrm{~nm}$ laser were synchronized by a commercial available delay/digital pulse generator. The LBO crystal was utilized for the SHG to $515 \mathrm{~nm}$ and the CLBO crystals were used for FHG to $258 \mathrm{~nm}$, SFG to $221 \mathrm{~nm}$, and SFG to $193 \mathrm{~nm}$. The generated $193 \mathrm{~nm}$ laser was operated at $6 \mathrm{kHz}$ with pulse duration of $4 \mathrm{~ns}$. The average power was $310 \mathrm{~mW}$ and the linewidth was about $4 \mathrm{GHz}$, which satisfied the needs for injection-seeding the hybrid ArF excimer laser [2,12]. As a higher-power $193 \mathrm{~nm}$ laser was needed to increase the signal-to-ASE-ratio of the hybrid ArF excimer laser output, a watt-level 193-nm laser has been generated due to this requirement [20]. 


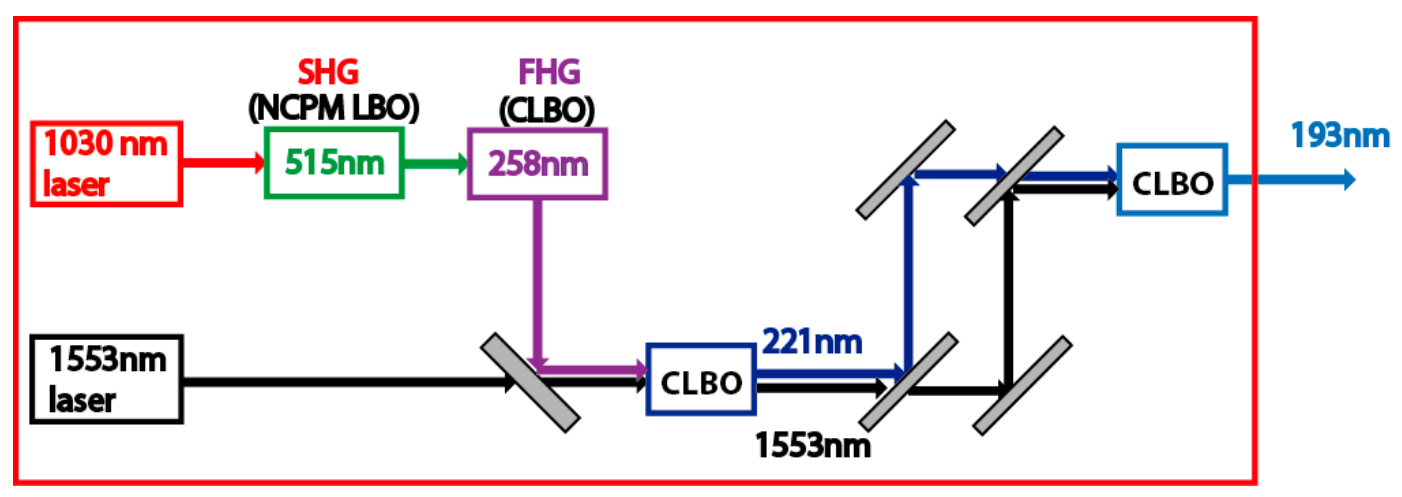

Figure 2. Schematic setup of $193 \mathrm{~nm}$ generation by frequency mixing of 1030-nm and 1553-nm lasers (NCPM: noncritical phase-matching).

\section{DUV Laser Generation Based on Diamond Raman Laser}

In this section, a new method to generate the $193 \mathrm{~nm}$ DUV laser is introduced, which is based on the diamond Raman laser scheme. In terms of the above methods of the $193 \mathrm{~nm}$ generation with $258 \mathrm{~nm}$ and $1553 \mathrm{~nm}$, there is a limitation for its power scaling. The power of $258 \mathrm{~nm}$ laser is improved to more than $10 \mathrm{~W}$ while the power of the $1553 \mathrm{~nm}$ laser is limited because of the lack of the amplification medium and methods. The output power of the current Er-doped fiber amplifier is less than $2 \mathrm{~W}$ which is limited due to the stimulated Brillouin scattering [42]. For the solid-state laser, the average output power was also no more than $1 \mathrm{~W}$ [43]. Hence, this longer wavelength is usually generated by use of OPO process pumped by the Nd- or Yb-doped lasers.

In the past few decades, many Raman materials have been studied [44-46], which showed the high conversion efficiency to the first Stokes light from $1 \mu \mathrm{m}$. The stimulated Raman scattering (SRS) laser is remarkable for the momentum conservation automatically determined by the scattered phonons, which will induce the Stokes light beam to be a high quality [22,47]. Particularly, by use of the chemical vapor deposition (CVD) diamond, the diamond Raman laser depicted a high power result of $100 \mathrm{~W}$ [22] and a high slope efficiency of $84 \%$ approaching the quantum limit [23]. In detail, the most interesting advantages of diamond includes the high Raman gain (pumping at $1030 \mathrm{~nm}, \mathrm{~g}_{\mathrm{R}}=13.5 \pm 2.0 \mathrm{~cm} / \mathrm{GW}$ ) and the large frequency shift of the 1st order Raman mode $\left(1332.5 \mathrm{~cm}^{-1}\right)[22,48]$, which could achieve a high-power operation and a sufficient frequency shift. Moreover, the high thermal conductivity $(2200 \mathrm{~W} / \mathrm{m} \cdot \mathrm{K})$, which is two to three orders of magnitude higher than conventional Raman materials, and the low thermal expansion coefficient of diamond $\left(1.1 \times 10^{-6} \mathrm{~K}^{-1}\right)$ will be helpful for power scaling to a high level as well as its high damage threshold [45-48]. Another important advantage of the diamond is the broad transmission band. Recently, the longest solid-state Raman laser wavelength was obtained in the 3- $\mu \mathrm{m}$ region in a CVD diamond, showing a new pathway to the mid-IR laser and the possibility to cover from NIR to mid-IR wavelength [49]. Hence, by choosing a suitable Raman wavelength, a high-power $193 \mathrm{~nm}$ laser will be effectively generated by stages of SFG.

Figure 3 demonstrates the conceptual setup of the high-power $193 \mathrm{~nm}$ laser by the diamond Raman laser. The idea is also basically based on two stages of SFG process. The first DUV wavelength is at $260 \mathrm{~nm}$, which is the FHG of a $1040 \mathrm{~nm}$ laser. Meanwhile, the wavelength of the NIR laser is $1512 \mathrm{~nm}$, which is the second Stokes wavelength of a $1078 \mathrm{~nm}$ laser and generated by a diamond Raman laser. Both the $1040 \mathrm{~nm}$ and $1078 \mathrm{~nm}$ laser come from one dual-wavelength Yb-doped fiber laser. Each laser is amplified by stages of fiber amplifier and $\mathrm{Yb}$-doped materials amplifier, respectively. 


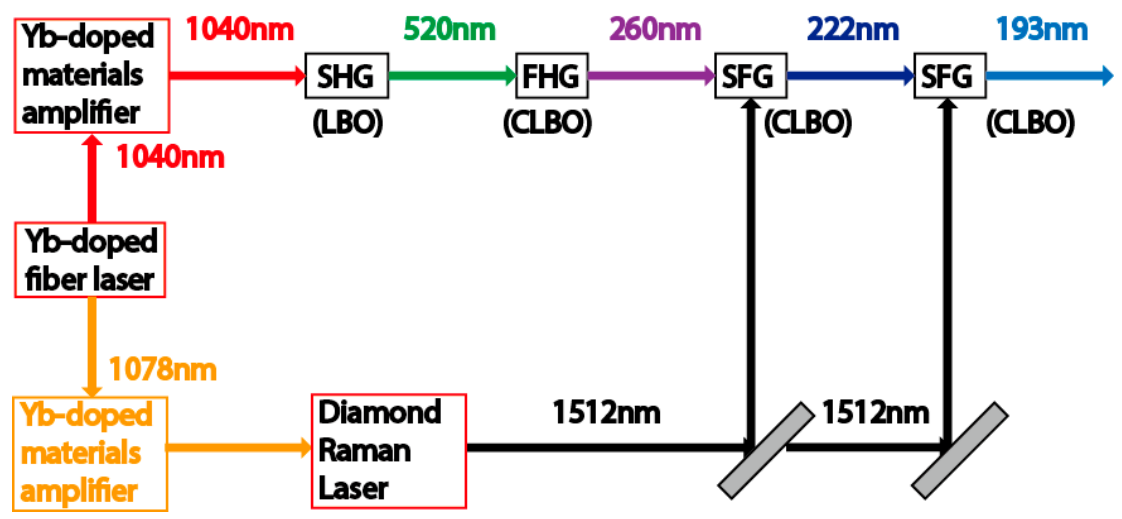

Figure 3. Conceptual setup of the $193 \mathrm{~nm}$ laser generation based on the diamond Raman laser.

The Yb-doped materials amplifier could be a $\mathrm{Yb}_{2} \mathrm{Lu}_{2} \mathrm{O}_{3}[50]$ or a $\mathrm{Yb}^{3+}: \mathrm{CaCdAlO}_{4}[51]$ laser at both wavelengths $(1040 \mathrm{~nm} \& 1078 \mathrm{~nm})$. For the frequency conversion by nonlinear crystals to short wavelengths, the $1040 \mathrm{~nm}$ laser generates the green laser at $520 \mathrm{~nm}$ by SHG using the LBO crystal, and then the DUV laser at $260 \mathrm{~nm}$ will be generated by SHG from $520 \mathrm{~nm}$ by use of the CLBO crystal. On the other hand, the $1078 \mathrm{~nm}$ is the pump laser of the diamond Raman laser; its 2nd Stokes wavelength of $1512 \mathrm{~nm}$ will be the NIR laser for the following SFG processes to $193 \mathrm{~nm}$. Hence, a DUV laser at $222 \mathrm{~nm}$ will be achieved by SFG between the 260-nm laser and the 1512-nm laser. The 193-nm laser will be generated by the second stage SFG between the 222-nm laser and the residual of the 1512-nm laser.

We first used a Yb:YAG laser at the wavelength of $1030 \mathrm{~nm}$ as the pump of the diamond Raman laser, which is the proof-of-principle experiment. For this proof-of-principle experiment, the Raman laser setup is depicted in Figure 4, of which is a short Raman laser cavity with a small piece of diamond inside it pumped by a $1030 \mathrm{~nm}$ laser [52]. The $1030 \mathrm{~nm}$ laser is from a $10 \mathrm{kHz}$ Yb:YAG CTR amplifier with the average power of $27 \mathrm{~W}$. The diamond is made by CVD process with a dimension of $6 \times 6 \times 1.5 \mathrm{~mm}^{3}$ and with anti-reflection (AR) coating of the pump, the 1st and the 2nd Stokes wavelengths. The beam radius of the $1030 \mathrm{~nm}$ pump laser is about $700 \mu \mathrm{m}$ [52]. The diamond crystal is pumped in the direction of $<110>$. The Raman laser cavity is a short and linear cavity with the length of $25 \mathrm{~mm}$ including an input concave mirror (M1) with $\mathrm{R}=75 \mathrm{~mm}$ and an output coupler (OC) with $\mathrm{R}=50 \mathrm{~mm}$. The coating of M1 is high transmission (HT) at $1030 \mathrm{~nm}$ and high reflection (HR) at the 1st $(1194 \mathrm{~nm})$ and the 2nd Stokes wavelength $(1420 \mathrm{~nm})$ of $1030 \mathrm{~nm}$. The OC is HR for both $1030 \mathrm{~nm}$ and $1194 \mathrm{~nm}$. The transmission of OC at $1420 \mathrm{~nm}$ was tried with three different values of $5 \%, 20 \%$, and $50 \%$. Two reflection mirrors (BB1-E04, Thorlabs Inc., Newton, NJ, USA) were applied to filter out the fundamental light, and the 2nd Stokes wavelength of $1420 \mathrm{~nm}$ was detected.

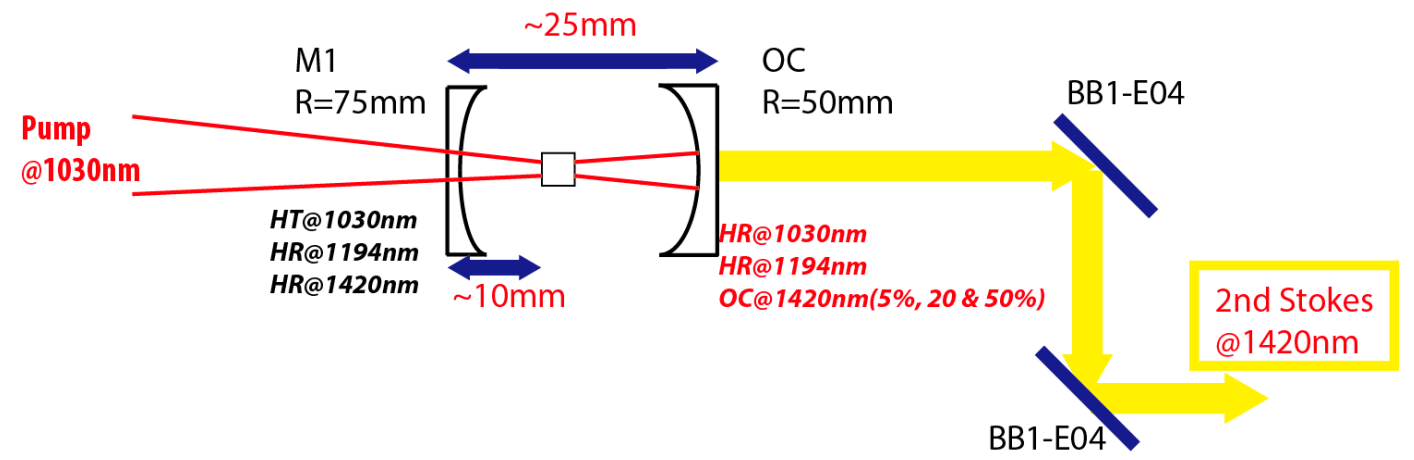

Figure 4. Experimental setup of the diamond Raman laser pumped by the Yb:YAG laser (HT: high transmission; HR: high reflection; OC: outup coupler). 
The Raman laser achieved lasing at the wavelength of $1420 \mathrm{~nm}$ when the pump laser power was above the threshold power. As shown in Figure 5, the threshold power was $1.25 \mathrm{~W}$ and $1.5 \mathrm{~W}$ for the $5 \%$ and $50 \%$ OC, respectively. The threshold power for $20 \%$ OC was between $1.25 \mathrm{~W}$ and $1.5 \mathrm{~W}$. During the cavity alignment to achieve the 2nd Stokes wavelength, the AR coating of the front surface of the diamond was easily damaged by the reflected pump beam back from the OC when the pump laser $(1030 \mathrm{~nm})$ power was higher than $3 \mathrm{~W}$. This was because of the imperfect design of the current Raman laser cavity. Not only the AR coating of the diamond surface but also the coating of the input mirror M1 was damaged by the returned pump laser. The values of the intensity of the returned pump laser at $\mathrm{M} 1$ and the front surface of the diamond were estimated to be $0.6-1 \mathrm{~J} / \mathrm{cm}^{2}$. The pump power was limited to $3 \mathrm{~W}$ to prevent the damages inside cavity for $5 \%$ and $20 \%$ OC. For the $50 \%$ OC, the pump power was carefully increased to about $4 \mathrm{~W}$ during the experiment, which was still at a lower power level in order to avoid the damage of the M1 and diamond. The HT coating of the pump beam at $\mathrm{OC}$ or the change of the radius of the curvature of could solve this issue to realize the higher power operation. At the pump power of $3 \mathrm{~W}$, the output power of the Raman laser was $130 \mathrm{~mW}, 293 \mathrm{~mW}$ and $325 \mathrm{~mW}$ using $5 \%, 20 \%$, and $50 \%$ OC, respectively. By use of the $50 \%$ OC, the highest average power of this Raman laser was $0.586 \mathrm{~W}$ when the pump laser was $4.2 \mathrm{~W}$ as shown in Figure 5, with the slope efficiency of $23 \%$ which was comparable to the previous reported results. The spectrum of the generated 2nd Stokes after the two reflection mirrors was measured by a spectrometer (NIRQuest512, Ocean Optics Inc., Largo, FL, USA) as shown in Figure 6.

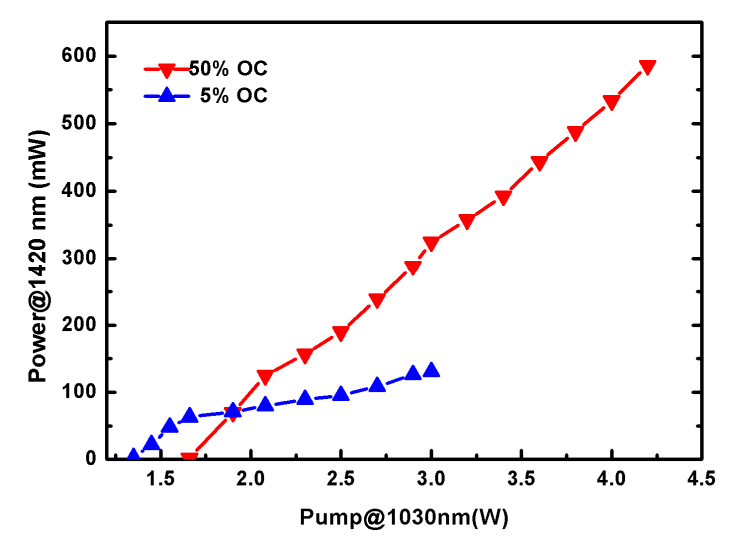

Figure 5. Output power of the 2nd Stokes (1420nm) vs. Pump power with 5\% and 50\% OC.

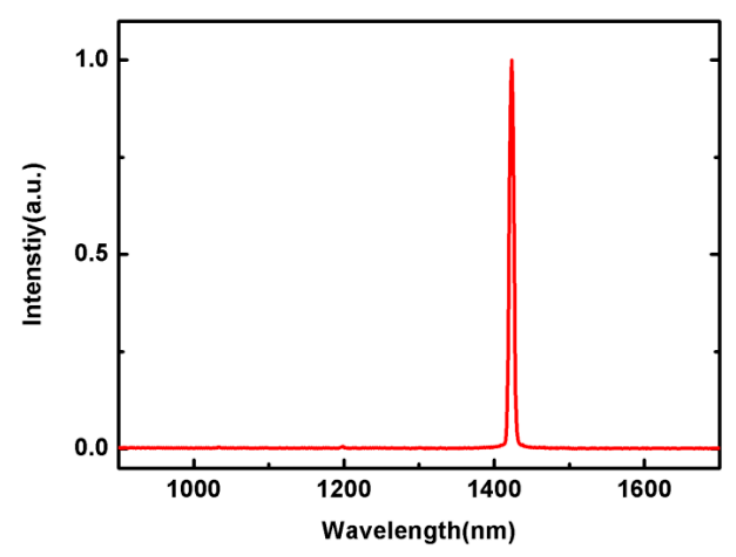

Figure 6. Spectrum of the diamond Raman laser at the 2nd Stokes wavelength of $1420 \mathrm{~nm}$. 
The pulse duration of the second Stokes light was shortened to $5 \mathrm{~ns}$ as shown in Figure $7 \mathrm{a}$, a single-shot picture from the oscilloscope, which is a common phenomenon in Raman laser [44] while the pulse duration of the pump laser was $10 \mathrm{~ns}$. The beam profile shown in Figure $7 \mathrm{~b}$ demonstrated a good beam quality as one of the merits of Raman laser, which would be beneficial to generate a 193-nm DUV laser with a high quality beam.

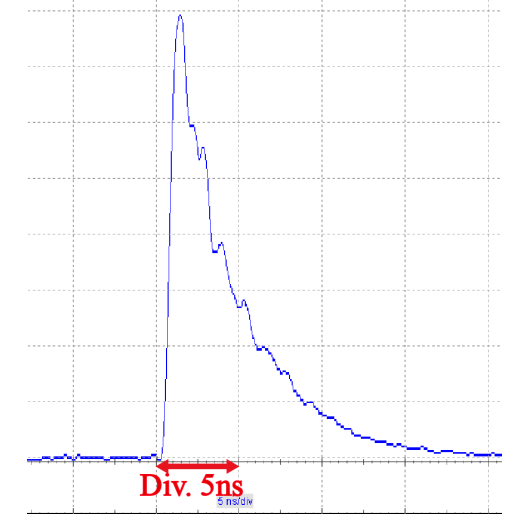

(a)

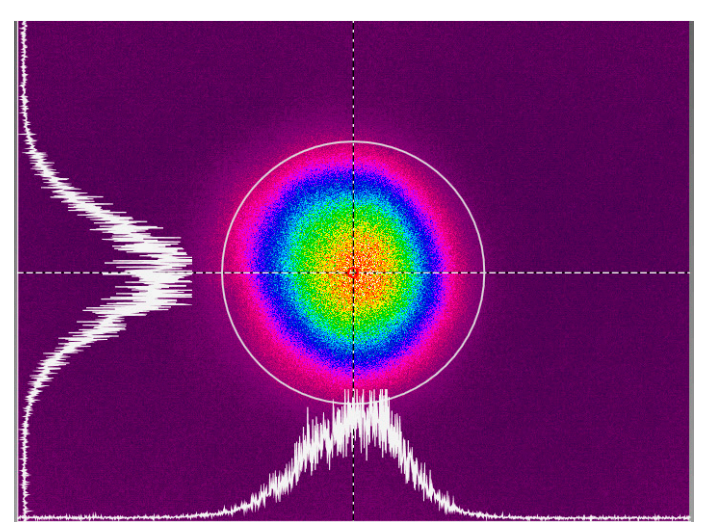

(b)

Figure 7. (a) Pulse duration of $\sim 5 \mathrm{~ns}(5 \%$ OC); (b) Beam profile of the $1420 \mathrm{~nm}$ laser.

According to the proof-of-principle experiment, the conversion efficiency of $23 \%$ implied the possibility of achieving high-power at the second Stokes wavelength of the Raman laser. If the pump laser of $1078 \mathrm{~nm}$ could be obtained at the average power of $50 \mathrm{~W}$, the output power of its 2nd Stokes wavelength at $1512 \mathrm{~nm}$ could be more than $10 \mathrm{~W}$. The design of the Raman laser cavity should be optimized in order to avoid the damage of the M1 and diamond surface. For instance, the current concave OC could be replaced by a plane mirror which could mitigate the power density on the surface of M1 and the diamond. Moreover, using high damage threshold coatings for M1 and diamond would also improve the output power without any damages. Then, the NIR laser at the 2nd Stokes wavelength could be high enough, as well as its good beam quality, to generate the final DUV laser at $193 \mathrm{~nm}$ with a high average power.

\section{Conclusions}

We summarized the current development status of the high-power DUV laser both at the wavelength of FHG of the 1- $\mu \mathrm{m}$ laser and at $193 \mathrm{~nm}$. The recent development of the solid-state/fiber laser, as well as the nonlinear optical crystals, prompts not only the average power but also the beam quality (coherence) of the DUV lasers to an unprecedented level. Moreover, combining the solid-state laser with other nonlinear process such as stimulated Raman scattering, NIR lasers could be achieved at new wavelengths with high power and high beam quality, which was tested by the proof-of-principle experiment. This Raman laser scheme provides a new route to the high-power DUV laser, especially at the wavelength of $193 \mathrm{~nm}$.

Acknowledgments: New Energy and Industrial Technology Development Organization (NEDO).

Conflicts of Interest: The authors declare no conflicts of interest.

\section{References}

1. Allaria, E.; Castronovo, D.; Cinquegrana, P.; Craievich, P.; Dal Forno, M.; Danailov, M.B.; D'Auria, G.; Demidovich, A.; De Ninno, G.; Di Mitri, S.; et al. Two-stage seeded soft-X-ray free-electron laser. Nat. Photonics 2013, 7, 913-918. [CrossRef] 
2. Tanaka, S.; Arakawa, M.; Fuchimukai, A.; Sasaki, Y.; Onose, T.; Kamba, Y.; Igarashi, H.; Qu, C.; Tamiya, M.; Oizumi, H.; et al. Development of high coherence high power $193 \mathrm{~nm}$ laser. In Proceedings of the SPIE Photonics West, Solid State Lasers XXV: Technology and Devices, San Francisco, CA, USA, 13-18 February 2016; Volume 9726, p. 972625. [CrossRef]

3. Liu, Q.; Yan, X.P.; Fu, X.; Gong, M.; Wang, D.S. High power all-solid-state fourth harmonic generation of $266 \mathrm{~nm}$ at the pulse repetition rate of $100 \mathrm{kHz}$. Laser Phys. Lett. 2009, 6, 203-206. [CrossRef]

4. Délen, X.; Deyra, L.; Benoit, A.; Hanna, M.; Balembois, F.; Cocquelin, B.; Sangla, D.; Salin, F.; Didierjean, J.; Georges, P. Hybrid master oscillator power amplifier high-power narrow-linewidth nanosecond laser source at $257 \mathrm{~nm}$. Opt. Lett. 2013, 38, 995-997. [CrossRef] [PubMed]

5. Chang, C.; Krogen, P.; Liang, H.; Stein, G.J.; Moses, J.; Lai, C.; Siqueira, J.P.; Zapata, L.E.; Kärtner, F.X.; Hong, K.-H. Multi-mJ, kHz, ps deep-ultraviolet source. Opt. Lett. 2015, 40, 665-668. [CrossRef] [PubMed]

6. Goldberg, L.; Cole, B.; McIntosh, C.; King, V.; Hays, A.D.; Chinn, S.R. Narrow-band 1 W source at 257 nm using frequency quadrupled passively Q-switched Yb:YAG laser. Opt. Express 2016, 24, 17397-17405. [CrossRef] [PubMed]

7. Müller, M.; Klenke, A.; Gottschall, T.; Klas, R.; Rothhardt, C.; Demmler, S.; Rothhardt, J.; Limpert, J.; Tünnermann, A. High-average-power femtosecond laser at $258 \mathrm{~nm}$. Opt. Lett. 2017, 42, 2826-2829. [CrossRef] [PubMed]

8. Nishioka, M.; Fukumoto, S.; Kawamura, F.; Yoshimura, M.; Mori, Y.; Sasaki, T. Improvement of laser-induced damage tolerance in $\mathrm{CsLiB}_{6} \mathrm{O}_{10}$ for high-power UV laser source. In Proceedings of the Lasers and Electro-Optics/Quantum Electronics and Laser Science Conference, Baltimore, MD, USA, 1-6 June 2003. [CrossRef]

9. Kojima, T.; Konno, S.; Fujikawa, S.; Yasui, K.; Yoshizawa, K.; Mori, Y.; Sasaki, T.; Tanaka, M.; Okada, Y. 20-W ultraviolet-beam generation by fourth-harmonic generation of an all-solid-state laser. Opt. Lett. 2000, 25, 58-60. [CrossRef] [PubMed]

10. Wang, G.; Geng, A.; Bo, Y.; Li, H.; Sun, Z.; Bi, Y.; Cui, D.; Xu, Z.; Yuan, X.; Wang, X.; et al. 28.4 W 266 nm ultraviolet-beam generation by fourth-harmonic generation of an all-solid-state laser. Opt. Commun. 2006, 259, 820-822. [CrossRef]

11. Novák, O.; Tuřcǐcová, H.; Smrž, M.; Miura, T.; Endo, A.; Mocek, T. Picosecond green and deep ultraviolet pulses generated by a high-power $100 \mathrm{kHz}$ thin-disk laser. Opt. Lett. 2016, 41, 5210-5213. [CrossRef] [PubMed]

12. Xuan, H.; Zhao, Z.; Igarashi, H.; Ito, S.; Kakizaki, K.; Kobayashi, Y. 300-mW narrow-linewidth deep-ultraviolet light generation at $193 \mathrm{~nm}$ by frequency mixing between Yb-hybrid and Er-fiber lasers. Opt. Express 2015, 23, 10564-10572. [CrossRef] [PubMed]

13. Xuan, H.; Qu, C.; Ito, S.; Kobayashi, Y. High-power and high-conversion efficiency deep ultraviolet (DUV) laser at $258 \mathrm{~nm}$ generation in the $\mathrm{CsLiB}_{6} \mathrm{O}_{10}(\mathrm{CLBO})$ crystal with a beam quality of $\mathrm{M}^{2}<1.5$. Opt. Lett. 2017, 42, 3133-3136. [CrossRef] [PubMed]

14. Wang, L.; Zhai, N.; Liu, L.; Wang, X.; Wang, G.; Zhu, Y.; Chen, C. High-average-power 266 nm generation with a $\mathrm{KBe}_{2} \mathrm{BO}_{3} \mathrm{~F}_{2}$ prism-coupled device. Opt. Express 2014, 22, 27086-27093. [CrossRef] [PubMed]

15. Liu, Q.; Yan, X.; Gong, M.; Liu, H.; Zhang, G.; Ye, N. High-power 266 nm ultraviolet generation in yttrium aluminum borate. Opt. Lett. 2011, 36, 2653-2655. [CrossRef] [PubMed]

16. Nikitin, D.G.; Byalkovskiy, O.A.; Vershinin, O.I.; Puyu, P.V.; Tyrtyshnyy, V.A. Sum frequency generation of UV laser radiation at $266 \mathrm{~nm}$ in LBO crystal. Opt. Lett. 2016, 41, 1660-1663. [CrossRef] [PubMed]

17. Fang, Z.; Hou, Z.-Y.; Yang, F.; Liu, L.-J.; Wang, X.-Y.; Xu, Z.-Y.; Chen, C.-T. High-efficiency UV generation at $266 \mathrm{~nm}$ in a new nonlinear optical crystal $\mathrm{NaSr}_{3} \mathrm{Be}_{3} \mathrm{~B}_{3} \mathrm{O}_{9} \mathrm{~F}_{4}$. Opt. Express 2017, 25, 26500-26507. [CrossRef] [PubMed]

18. Sakuma, J.; Kaneda, Y.; Oka, N.; Ishida, T.; Moriizumi, K.; Kusunose, H.; Furukawa, Y. Continuous-wave $193.4 \mathrm{~nm}$ laser with $120 \mathrm{~mW}$ output power. Opt. Lett. 2015, 40, 5590-5593. [CrossRef] [PubMed]

19. Jacob, J.J.; Merriam, A.J. Development of a 5-kHz solid state 193-nm actinic light source for photomask metrology and review. In Proceedings of the SPIE, 24th Annual BACUS Symposium on Photomask Technology, Monterey, CA, USA, 13-17 September 2004; Volume 5567. [CrossRef]

20. Xuan, H.; Qu, C.; Zhao, Z.; Ito, S.; Kobayashi, Y. 1 W solid-state $193 \mathrm{~nm}$ coherent light by sum-frequency generation. Opt. Express 2017, 25, 29172-29179. [CrossRef] 
21. Mead, R.D.; Hamilton, C.E.; Lowenthal, D.D. Solid state lasers for 193-nm photolithography. In Proceedings of the SPIE, Optical Microlithography X, Santa Clara, CA, USA, 10-14 March 1997; Volume 3051. [CrossRef]

22. Williams, R.; Kitzler, O.; McKay, A.; Mildren, R. Investigating diamond Raman lasers at the $100 \mathrm{~W}$ level using quasi-continuous-wave pumping. Opt. Lett. 2014, 39, 4152-4155. [CrossRef] [PubMed]

23. Sabella, A.; Piper, J.A.; Mildren, R.P. $1240 \mathrm{~nm}$ diamond Raman laser operating near the quantum limit. Opt. Lett. 2010, 35, 3874-3876. [CrossRef] [PubMed]

24. Nubbemeyer, T.; Kaumanns, M.; Ueffing, M.; Gorjan, M.; Alismail, A.; Fattahi, H.; Brons, J.; Pronin, O.; Barros, H.G.; Major, Z.; et al. 1 kW, 200 mJ picosecond thin-disk laser system. Opt. Lett. 2017, 42, 1381-1384. [CrossRef] [PubMed]

25. Rothhardt, J.; Rothhardt, C.; Müller, M.; Klenke, A.; Kienel, M.; Demmler, S.; Elsmann, T.; Rothhardt, M.; Limpert, J.; Tünnermann, A. $100 \mathrm{~W}$ average power femtosecond laser at $343 \mathrm{~nm}$. Opt. Lett. 2016, 41, 1885-1888. [CrossRef] [PubMed]

26. Lesparre, F.; Martial, I.; Didierjean, J.; Gomes, J.T.; Pallmann, W.; Resan, B.; Loescher, A.; Negel, J.-P.; Graf, T.; Ahmed, M.A.; et al. High-power Yb:YAG single-crystal fiber amplifiers for femtosecond lasers. In Proceedings of the SPIE Photonics West, Solid State Lasers XXV: Technology and Devices, San Francisco, CA, USA, 7-12 February 2015; Volume 9432. [CrossRef]

27. Scholz, M.; Opalevs, D.; Leisching, P.; Kaenders, W.; Wang, G.; Wang, X.; Li, R.; Chen, C. A bright continuous-wave laser source at $193 \mathrm{~nm}$. Appl. Phys. Lett. 2013, 103, 051114. [CrossRef]

28. Zhang, H.; Wang, G.; Guo, L.; Geng, A.; Bo, Y.; Cui, D.; Xu, Z.; Li, R.; Zhu, Y.; Wang, X.; et al. 175 to 210 nm widely tunable deep-ultraviolet light generation based on KBBF crystal. Appl. Phys. B 2008, 93, 323-326. [CrossRef]

29. Kanai, T.; Wang, X.; Adachi, S.; Watanabe, S.; Chen, C. Watt-level tunable deep ultraviolet light source by a KBBF prism-coupled device. Opt. Express 2009, 17, 8696-8703. [CrossRef] [PubMed]

30. Ito, S.; Onose, T.; Watanabe, S.; Kanai, T.; Kakizaki, K.; Matsunaga, T.; Chen, C.; Kobayashi, Y.; Zhou, C.; Fujimoto, J.; et al. A Sub-Watt, Line-narrowing, 193-nm Solid State Laser Operating at $6 \mathrm{kHz}$ with KBBF for Injection-locking ArF excimer laser systems. In Proceedings of the Lasers, Sources, and Related Photonic Devices, San Diego, CA, USA, 29 January-3 February 2012. [CrossRef]

31. Kawai, H.; Tokuhisa, A.; Doi, M.; Miwa, S.; Matsuura, H.; Kitano, H.; Owa, S. UV light source using fiber amplifier and nonlinear wavelength conversion. In Proceedings of the Lasers and Electro-Optics/Quantum Electronics and Laser Science Conference, Baltimore, MD, USA, 1-6 June 2003.

32. Nakazato, T.; Tsuboi, M.; Onose, T.; Tanaka, Y.; Sarukura, N.; Ito, S.; Kakizaki, K.; Watanabe, S. Development of high coherence, $200 \mathrm{~mW}, 193 \mathrm{~nm}$ solid-state laser at $6 \mathrm{kHz}$. In Proceedings of the SPIE Photonics West, Solid State Lasers XXV: Technology and Devices, San Francisco, CA, USA, 7-12 Februray 2015; Volume 9342. [CrossRef]

33. Umemura, N.; Ando, M.; Suzuki, K.; Takaoka, E.; Kato, K.; Hu, Z.; Yoshimura, M.; Mori, Y.; Sasaki, T. 200-mW-average power ultraviolet generation at $0.193 \mu \mathrm{m}$ in $\mathrm{K}_{2} \mathrm{Al}_{2} \mathrm{~B}_{2} \mathrm{O}_{7}$. Appl. Opt. 2003, 42, 2716-2719. [CrossRef] [PubMed]

34. Ringling, J.; Kittelmann, O.; Seifert, F.; Noack, F.; Korn, G.; Squier, J.A. Femtosecond solid state light sources tunable around $193 \mathrm{~nm}$. In Proceedings of the SPIE, Generation, Amplification, and Measurement of Ultrashort Laser Pulses, Los Angeles, CA, USA, 23-29 January 1994; Volume 2116. [CrossRef]

35. Tran, T.T.; Yu, H.; Rondinelli, J.M.; Poeppelmeier, K.R.; Halasyamani, P.S. Deep Ultraviolet Nonlinear Optical Materials. Chem. Mater. 2016, 28, 5238-5258. [CrossRef]

36. Yang, Y.; Jiang, X.; Lin, Z.; Wu, Y. Borate-Based Ultraviolet and Deep-Ultraviolet Nonlinear Optical Crystals. Crystals 2017, 7, 95. [CrossRef]

37. Trabs, P.; Noack, F.; Aleksandrovsky, A.S.; Zaitsev, A.I.; Petrov, V. Generation of coherent radiation in the vacuum ultraviolet using randomly quasi-phase-matched strontium tetraborate. Opt. Lett. 2016, 41, 618-621. [CrossRef] [PubMed]

38. Nakazato, T.; Ito, I.; Kobayashi, Y.; Wang, X.; Chen, C.; Watanabe, S. $149.8 \mathrm{~nm}$, the shortest wavelength generated by phase matching in nonlinear crystals. In Proceedings of the SPIE Photonics West, Nonlinear Frequency Generation and Conversion: Materials and Devices XVI, San Francisco, CA, USA, 28 January2 February 2017; Volume 10088, p. 1008804. [CrossRef]

39. Nakazato, T.; Ito, I.; Kobayashi, Y.; Wang, X.; Chen, C.; Watanabe, S. Phase-matched frequency conversion below $150 \mathrm{~nm}$ in $\mathrm{KBe}_{2} \mathrm{BO}_{3} \mathrm{~F}_{2}$. Opt. Express 2016, 24, 17149-17158. [CrossRef] [PubMed] 
40. Liu, G.; Wang, G.; Zhu, Y.; Zhang, H.; Zhang, G.; Wang, X.; Zhou, Y.; Zhang, W.; Liu, H.; Zhao, L.; et al. Development of a vacuum ultraviolet laser-based angle-resolved photoemission system with a super high energy resolution better than $1 \mathrm{meV}$. Rev. Sci. Instrum. 2008, 79, 023105. [CrossRef] [PubMed]

41. Chen, C.; Sasaki, T.; Li, R.; Wu, Y.; Lin, Z.; Mori, Y.; Hu, Z.; Wang, J.; Uda, S.; Yoshimura, M.; et al. Nonlinear Optical Borate Crystals: Principles and Applications; Wiley-VCH Verlag \& Co. KGaA: Weinheim, Germany, 2012; pp. 164-166. ISBN 978-3-527-41009-5.

42. Zhao, Z.; Xuan, H.; Igarashi, H.; Ito, S.; Kakizaki, K.; Kobayashi, Y. Single frequency, 5 ns, 200 J, 1553 nm fiber laser using silica based Er-doped fiber. Opt. Express 2015, 23, 29764-29771. [CrossRef] [PubMed]

43. Tolstik, N.A.; Kurilchik, S.V.; Kisel, V.E.; Kuleshov, N.V.; Maltsev, V.V.; Pilipenko, O.V.; Koporulina, E.V.; Leonyuk, N.I. Efficient $1 \mathrm{~W}$ continuous-wave diode-pumped Er,Yb:YAl3(BO3)4 laser. Opt. Lett. 2007, 32, 3233-3235. [CrossRef] [PubMed]

44. Pask, H.M. The design and operation of solid-state Raman lasers. Prog. Quantum Electron. 2003, $27,3-56$. [CrossRef]

45. Zverev, P.G.; Basiev, T.T.; Osiko, V.V.; Kulkov, A.M.; Voitsekhovskii, V.N.; Yakobson, V.E. Physical, chemical and optical properties of barium nitrate Raman crystal. Opt. Mater. 1999, 11, 315-334. [CrossRef]

46. Kaminskii, A.A.; McCray, C.L.; Lee, H.R.; Lee, S.W.; Temple, D.A.; Chyba, T.H.; Marsh, W.D.; Barnes, J.C.; Annanenkov, A.N.; Legun, V.D.; et al. High efficiency nanosecond Raman lasers based on tetragonal $\mathrm{PbWO}_{4}$ crystals. Opt. Commun. 2000, 183, 277-287. [CrossRef]

47. McKay, A.; Kitzler, O.; Mildren, R.P. Simultaneous brightness enhancement and wavelength conversion to the eye-safe region in a high-power diamond Raman laser. Laser Photonics Rev. 2014, 8, L37-L41. [CrossRef]

48. Feve, J.-P.M.; Shortoff, K.E.; Bohn, M.J.; Brasseur, J.K. High average power diamond Raman laser. Opt. Express 2011, 19, 913-922. [CrossRef] [PubMed]

49. Sabella, A.; Piper, J.A.; Mildren, R.P. Diamond Raman laser with continuously tunable output from 3.38 to $3.80 \mu \mathrm{m}$. Opt. Lett. 2014, 39, 4037-4040. [CrossRef] [PubMed]

50. Weichelt, B.; Wentsch, K.S.; Voss, A.; Ahmed, M.A.; Graf, T. A 670 W Yb: $\mathrm{Lu}_{2} \mathrm{O}_{3}$ thin-disk laser. Laser Phys. Lett. 2012, 9, 110-115. [CrossRef]

51. Boudeile, J.; Druon, F.; Hanna, M.; Georges, P.; Zaouter, Y.; Cormier, E.; Petit, J.; Goldner, P.; Viana, B. Continuous-wave and femtosecond laser operation of $\mathrm{Yb}: \mathrm{CaGdAlO}_{4}$ under high-power diode pumping. Opt. Lett. 2007, 32, 1962-1964. [CrossRef] [PubMed]

52. Xuan, H.; Ito, S.; Kobayashi, Y. High power Yb:YAG ceramics laser and diamond Raman laser for frequency conversion to DUV. In Proceedings of the 8th International Symposium on Ultrafast Phenomena and Terahertz Waves, Chongqing, China, 10-12 October 2016. [CrossRef] 